\title{
A INDEPENDÊNCIA DA FUNÇÃO REGULADORA E OS ENTES REGULADORES INDEPENDENTES
}

\author{
FRANCISCO DE QUEIROZ BEZERRA CAVALCANTI*
}

1. A idéia de aprimoramento do exercício pelo Estado de funções reguladoras cresce e ganha importância na medida em que ele afasta-se do papel de agente das atividades reguladas. Enquanto assumia esse duplo papel a premência do controle parecia não existir, embora, em muitas situações fosse patente a ineficiência da atuação estatal e a lacuna quanto à regulação das atividades exercidas. Aquela necessidade de exercício do poder regulador e de polícia é observável com maior nitidez no tocante às atividades econômicas, sobretudo, quando o Estado de seu exercício se afasta, passando a serem essas atividades exercidas por empresas privadas, cuja atuação se pauta, normalmente, na idéia de lucro, com redução de custos e aumento dos preços de bens e serviços. Juan Carlos CASSAGNE bem destaca tal fato ao lembrar que

"el fenómeno de la privatización al abarcar la transferencia al sector privado de la gestión de los servicios públicos que antes prestaban empresas estatales, há generado la correlativa necesidad de regular esas actividades para proteger debidamente los intereses de la comunidad".

1 CASSAGNE, Juan Carlos. La intervencion administrativa. Buenos Aires, 1994: Abeledo Perrot, p.151.

* Professor titular de Direito Administrativo da Faculdade de Direito do Recife [UFPE], Doutor em Direito e Juiz Federal.

R. Dir. Adm.,

Rio de Janeiro, 219: 253-270, jan./mar. 2000 
No mesmo sentido poder-se-ia citar, dentre tantos outros, Patrícia Raquel MARTÍNEZ' e Carlos Ari SUNDFELD'. Verifica-se 'a medida em que o Estado deixa de ser ele mesmo, por si, ou através de pessoa jurídica sob seu controle, o responsável por uma atividade econômica ou social, cresce a necessidade de aperfeiçoamento do sistema regulador, do decorrente poder de polícia, inclusive quanto à efetividade dessa regulação. Tal aperfeiçoamento do sistema regulador resultará, em proveito, ao final, dos próprios usuários dos serviços. Essa idéia norteadora da melhoria da qualidade do serviço vem se destacando até mesmo em relação aos próprios serviços que remanescem exercendo-se diretamente através do Estado, ou de suas empresas, ou de pessoas jurídicas administrativas. Não se olvide, no caso brasileiro, a recente introdução explícita do princípio da eficiência, algo já, evidentemente existente, de modo implícito, no sistema, mas sem o rol de consequiências decorrentes da Emenda Constitucional $\mathrm{n}^{\circ} 19 / 98$. Relacionada a esse princípio encontra-se a previsão do vigente texto constitucional, da lei disciplinando a participação dos usuários na Administração Pública direta e indireta ${ }^{4}$. Essa figura, aliás, já é existente em inúmeros dos ordenamentos jurídicos que, usualmente, servem de referência ao Brasil. ${ }^{5}$

1.1 No tocante ao novo perfil da Administração Pública, pode-se afirmar, seguindo lição da doutrina italiana, que ela evoluiu e está a evoluir daquilo que se denominava "amministrazione di erogazione [gestione dei servizi]", para "amministrazione di regolazione". Mudança essa de perfil que algumas consequiências fundamentais, como ressalta Maria Alessandra STEFANELLI,

"si tutto ciò gioca la sempre maggiore frammentazione della societá, per la presenza le per il reconoscimiento di rilevanza giuridical di una molteplicità sempre crescente di interessi in essa presente:il che consegue la trasformazione dello stato in stato pluriclasse, nel quale il problema maggiore diviene per

2 MARTÍNEZ, Patrícia Raquel. Sistema de control de los servicios públicos "privatizados"en la Argentina, in L_L Los Servicios Publicos . Regimen Jurídico actual. Buenos Aires, 1994: Depalma, p.136/137

3 SUNDFELD, Carlos Ari. Direito Administrativo Ordenador. São Paulo, 1997: Malheiros, p.20 e segs.

4 Prevê a Constituição, no texto emendado:

Art.37...

Parágrafo $3^{\circ}$ A Lei disciplinará as formas de participação do usuário na Administração Pública direta e indireta, regulando especialmente:

I - As reclamações relativas à prestação dos serviços públicos em geral, asseguradas a manutenção de serviços de atendimento do usuário e a avaliação periódica, externa e interna, da qualidade dos serviços;

II - O acesso dos usuários e registros administrativos e a informaçāo sobre atos de governo, observado o disposto no Art. $5^{\circ}, \mathrm{X}, \mathrm{XXXIII}$;

III - A disciplina da representação contra o exercício negligente ou abusivo de cargo, emprego ou funçāo na Administração Pública.

5 Na própria América Latina já se encontram textos legais nesse sentido, como p.ex., no caso Argentino com a Lei 24.240 e o Decreto Regulamentar 1.798/94, como ressalta Juan M. FARINA em Defensa del consumidor y del usuario. Buenos Aires: Astrea, 1995. 
l'appunto contemporare tra loro gli interessi di settore; va da sé che in questa trasformazione è sempre più difficile la reductio ad unun, $e$ cioè il ricondurre questa varietá di interessi a quella unità [teorica piùche reale] che è costituitá dall 'interesse pubblico" 6

Essa idéia de pluralidade de interesses públicos, da inexistência de efetiva unidade não é aprofundada pela doutrina brasileira, mas é algo inarredável. Às vezes o pragmatismo supera a teoria, fazendo surgir novas construções teóricas fruto das acomodações. A necessidade de regulações específicas e relativamente independentes é algo inafastável e já percebido por doutrinadores como Sabino CASSESSE, que, tendo como pano de fundo a Itália, lecionava, algo nem sempre observado pelos administrativistas, que

“la Administración Italiana es - como hoy todas las de los paises desarrollados - multiorganizativa, en el sentido de quel ámbito y la variedad de las funciones públicas no sólo han hecho desaparecer la unidad de la organización en torno al Estado, sino que han impulsado y aplicado modelos organizativos diversos. Las Administraciones Públicas están, portanto o fragmentadas, o diferenciadas. Por este motivo es preferible decir que la administración es multiorganizativa antes que pluralista o policéntrica"7

Partindo-se da existência de focos de regulação cada vez mais nítidos, devidamente identificados e segmentados, surgiu a necessidade da existência de Entes Reguladores autônomos. Esse poder regulador exercido por entes reguladores autônomos encontra maiores dificuldades, conforme se verá mais adiante, em Estados como o Brasil, onde o poder regulamentar está, ao menos teoricamente, mais subordinado à moldura legislativa e ao papel de ser mero instrumento de aplicação das leis, diferentemente de outros Estados, nos quais flui esse poder de produção de normas secundárias, com maior facilidade, que são aqueles nos quais o ordenamento jurídico contempla a existência de "regulamentos autônomos" e a existência de centros regulamentadores em pessoas jurídicas sem capacidade política.

1.1.1 É natural que a figura do "Ente Regulador" relativamente autônomo e também, as técnicas reguladoras tenham se desenvolvido, inicialmente, em Estados nos quais tenha havido, historicamente, menor participação do setor público no exercício das atividades produtivas, sentindo-se, pois, com mais intensidade e mais precocemente, a necessidade de rigoroso e efetivo disciplinamento das atividades econômicas exercidas por particulares, não só no interesse direto dos usuários, mas,

6 STEFANELl, Maria Alessandra. La tutela dell 'utente di pubblici servizi. Padova, 1994: Cedam, p. 02/03.

7 CASSESSE, Sabino. Las bases del derecho administrativo. Madrid, 1994: Instituto Nacional de Administracion Publica, p. 154. 
também. no de serem evitados abusos do poder econômico, ou pelo menos de serem minorados os efeitos desses abusos.

O exemplo dos EUA é, naturalmente lembrado. "Nos Estados Unidos, a legislação antitruste sobreveio à existência e consolidação da grande concentração econômica ocorrida a partir de meados do século XIX... as medidas destinadas a fortalecer a concorrência foram utilizadas ainda no regime do common law... A crescente onda de concentração de gigantes na Segunda metade do século $X I X$ representada pelas ferrovias e pelos trustes, levou ao surgimento do Sherman anti-trust Act, em 1890 e continuando., ainda a situação de abuso, à adoção do Clayton Act e à criação da Federal Trade Commission em 1914." " 9

Ressalte-se, ainda que foi, também, no sistema norte americano que primeiramente surgiu e desenvolveu-se a proteção ao consumidor, a partir de Act de $1872 .^{10}$

Relevante se lembrar que a necessidade de regular atividades e a opção pela criação de entes reguladores não surgiu com a mesma intensidade e nem nos mesmos momentos nos vários ordenamentos jurídicos. Foi modelo originário dos EUA e do Reino Unido paulatinamente acolhido a adaptado, por vezes com dificuldade, fruto até das molduras constitucionais existentes, por outros ordenamentos jurídicos, nos quais nem sempre obteve idênticas respostas, nem gerou idênticos institutos, mas, de qualquer sorte, as figuras que surgiram em decorrência apresentam traços aglutinadores e caracterizadores muito fortes que indicam as fontes inspiradoras, basicamente a referida, norte americana e com menor relevo a britânica.

1.1.2 Michel GENTOT, por exemplo, ao referir-se à origem das autoridades administrativas independentes na França, lecionava no sentido

que "la création et le développement des autorités administratives indépendentes sont souvent expliqués par un souci de pragmatisme s'apposant aux traditions de jurisdisme,d'egualitarisme et de rigueur cartésienne par lesquelles on définit souvent l'administration française, par la recherche d'une capacité d'expertise d'innovation et d'adaptabilite dont seraient dépourveus les structures classiques et par une défiance à l'egard d'un État bureucratique et routinier qui tiendrait un compte insuffisant des libertés individuelles. Cette triple justification conduittout naturellement à recherceher un modèle de référence dans la tradition anglo-saxonne". 11

8 FONSECA, João Bosco Leopoldino da. Lei de Proteção da concorrência. Comentários à lei antitruste. Rio de Janeiro, 1995: Forense, p.15.

9 No mesmo sentido consulte-se Waldirio BULGARELLI. Concentração de empresas e Direito antitruste. São Paulo, 1996: Atlas, $2^{\mathbf{a}}$ ed., p.35 e segs.

10 EPSTEIN, David; NICKLES, Steve H. Consumer Law. St.Paul, Minn, 1981: West. Publishing, p.05.

11 GENTOT, Michel. Les autorités administratives indépendentes. Paris, 1994: Montchrestien, p.19. 
Ressalve-se, entretanto, que GENTOT, embora reconhecendo a inspiração anglo-saxônica do modelo tenta encontrar os principais elementos do instituto francês na própria França. ${ }^{12}$

A grande maioria dos doutrinadores reconhece, entretanto, o modelo norte-americano de AGÊNCIAS REGULADORAS como a principal fonte inspiradora para o surgimento de institutos similares, ou pelo menos com inúmeras de suas características, para atender à finalidade básica para a qual aquelas existem, na Europa ocidental e em vários Estados latino-americanos.

1.2 AS AGÊNCIAS têm sido, efetivamente, um dos pilares da administração Pública nos EUA e é, normalmente, com a criação delas que o Estado americano procura responder aos anseios de participação do setor público na disciplina da vida em sociedade.

É o que lecionam GELLHOHORN e LEVIN, ao destacar que " Administrative Agencies usually are created to deal with current crises or to redress serious social problems. Through out the modern era of administrative regulation, which began approximately a century ago, the Government's response to a public demand for action has often been to establish a new Agency or to grant new powers to a existing bureaucracy. Near the turn of the century, Agencies like the Interstate Commerce Commisision and The Federal Trade Commission were created in the attempt to control the anticompetitive conduct of monopolies and powerful corporations". ${ }^{13}$

A figura das Agências é uma constante e até crescente no "Administrative Law" norte-americano, dentre elas se destacando, como espécie, as Regulatory Agencies. Segundo Cass R. SUNSTEIN, nos EUA, antes de 1900 existiam apenas seis grandes Agências na administração Federal, incluindo a Interstate Commerce Commission [1887] e a Comptroller of the Currency [1863]. Na década entre $1900 \mathrm{e} 1910$ apenas uma Agência Reguladora foi criada, a Antitrust Division. No período entre 1910 e e 1920 surgiram mais cinco novas Agências Reguladoras, dentre elas destacando-se a Federal Trade Commision [1914] e a Federal Power Commision [1920]. Na década entre 1920 e 1930 foram criadas apenas duas. Na década do "New Deal" o congresso norte americano criou dez novas Agências, além de outras entidades que, embora não incluídas no rol das Agências Reguladoras exerciam funções como spending, taxing, insurance. De 1940 até 1960 foram criadas apenas quatro Agências e na década de sessenta, sete.

Nos anos setenta, entretanto, "no fewer than twenty- one agencies were created by far the most explosive period of regulatory growth in the nation's history. In the period1970-1980 the most dramatic changes occured in the area of social

12 GENTOT, Michel. Obra citada, p.20.

13 GELLHORN, Ernst; LEVIN. Administrative Law and Process. St. Paul, Minn., 1997: West Publishing, p.01. 
regulation [defined to include consumer safety and health, job safety and working conditions and environment and energy/ rather than economic regulations". ${ }^{4}$

Verifica-se, no caso norte americano, tendência de fortalecimento do Estado Regulador, compreensível e compatível com o papel traçado para o Ele nos EUA, de regulador, disciplinador da iniciativa privada, do exercício por ela de atividades econômicas, culturais e sociais, postura imprescindível em um país no qual as atividades empresarias são exercidas, basicamente, pela iniciativa privada. A proteção a valores e bens como a saúde, o meio ambiente, o trabalho, o consumo, a concorrência etc. tem sido objeto de adequada atividade reguladora e de eficiente exercício do decorrente poder de polícia pelas Agências Reguladoras através do exercício de poderes como "rule making power, licencing power, power over business. É importante observar que o "rule making power" apresenta-se como bem mais amplo que o poder de expedir normas secundárias por entes reguladores como os brasileiros e, por outro lado, não se deve olvidar que o controle judicial sobre os atos das "Regulatory Agencies" americanas não tem a amplitude do controle judicial previsto na Constituição Brasileira, sobre a Administração pública, inclusive, entes reguladores. Há, ressalte-se, previsão no Federal Administrative Procedure Act [APA, de 1946], de exclusão de controle judicial em relação a determinadas competências das Agencias Reguladoras. Prevê aquele diploma legal que a judicial review é cabível, except to the extent that -1 - statutes preclude judcial review; or 2 - Agency Action is committed to Agency discretion by Law. Naturalmente, a doutrina e a jurisprudência se fixaram no sentido não ser tal previsão aplicável em se tratando da proteção de direitos e liberdades de fundo constitucional, ou quando o agir da Agencia se caracterizar como arbitrary, capricious, an abuse of discretion".

1.2.1 Deve-se ressaltar, por outro lado, que a expressão Agency, no Direito Norte americano, tem um sentido amplo, pode-se dizer, extremamente amplo. Bernard SCHWARTZ, fundado no APA federal, de 1946, chega a apresentar seu contorno, ao qual se chega por exclusão de alguns entes políticos e representativos da soberania do Estado. Afirma aquele jurista que "Agencies means each authority of the Government of the United States, whether or not it is within or subject to review by another Agency, but does not include
(A) the Congress
(B) the courts of the United States
(C) the Governments of the territories of the United States
(D) the Government of the District of Columbia" 15

14 SUNSTEIN, Cass R. After the rights revolution-Reconceiving the Regulatory State. London, Cambridge, Massachussets, Harvard. 1990: University Press, p.242/243.

15 SCHWARTZ, Bernard. Administrative Law. Boston and Toronto, 1977: Little, Brown and Company, p.05. 
Verifica-se que Agência corresponde, basicamente, a muitas das unidades que compõem a Administração Federal norte americana, excluídos os órgãos diretamente integrantes do Executive Office of the President, os Departments a ele vinculados, como Department of State, Department of Justice etc. e as Government Corporations. É relevante, ainda, destacar que o gênero Agência, nos EUA, comporta classificação em duas espécies: regulatory agency e non-regulatory agency. Esse segundo tipo corresponde àquelas que, no dizer de SCHWARTZ, são investidas "with authority to dispense benefits for promotion social, and economics welfare, such as pensions and government insurance"16. São unidades para prestação de serviços públicos quando não exercidos através da Administração centralizada. É um eficiente instrumento para exercício das funçōes administrativas, mas com poderes bem mais limitados que os do primeiro tipo, ou seja as regulatory agencies. Essas, por sua vez, se caracterizam pela maior independência e pelo poder que a qualifica, o regulador. São aquelas "with authority to regulate the economic activities of the individuals and businesses. They have the power to prescribe generally what shall or shall not be done in a given situation (just as legislative dol to determine whether the law has been violated in a particular case and to proceed against violators ljust as prosecutors and Courts dol; and even to impose fines and render what amount to money judgments. Agencies vested with these powers are usually called regulatory agencies because their activities impinge upon the rights of private individuals and regulate manner in which such rights may be exercised." 17

É exatamente essa espécie de pessoa jurídica, autônoma, com capacidade de produção normativa reguladora, com poderes discricionários, com capacidade de precisar conceitos indeterminados, com mecanismos de controle sobre ela mais limitados, com maior autonomia e com estabilidade de seus dirigentes, que serviu de fonte inspiradora para a criação de entes reguladores autônomos em outros sistemas jurídicos que adotavam modelos mais centralizadores e monolíticos para exercício das funções administrativas, inclusive no campo da regulamentação e do exercício do poder de polícia.

1.3 Outro modelo de Administração descentralizada, com base em entes autônomos, sempre referenciado, é o do Reino Unido. Inclusive, ressalta-se a importância daquele modelo até em função de se tratar de algo já antigo. A preocupação da reforma do Estado, e da função administrativa naquele Estado não é tão recente, ou já vem de longa data como lembra Kate JENKINS e um dos pilares desse sistema construído é a figura da agência. Ressalta aquela Autora, examinando a nova estrutura ali existente que "o serviço público agora possui cerca de $65 \%$ de seu contingente trabalhando em agências. Elas variam em tamanho, de muito pequenas - um centro de conferências, com staff de 20 pessoas - até as enormes agências de benefícios, com 30 a 40 mil servidores. Os traços caracteristicos dessas agências é terem sistemas de gestāo separados da administração central e estarem cada vez mais gerindo seus próprios staffs, pagamentos e negociações, e trabalharem mediante 
acordo com seus Departamentos [secretarias] responsáveis, conhecido como documentos de referência" ${ }^{18}$ Em verdade, a tradição no sentido da descentralização da Administração pública no Reino Unido, já é secular."

The eighteenth and early nineteenth centuries saw a proliferation of special statutory bodies. These were created by Parliament to deal with the social problems caused by the industrial revolution. They, included Improvement Commisioners, Boards and Health, Poor Law Bodies, Turnpike Trusts and operate outside the hierarchy of ministerial responsibility" ${ }^{19}$, entendendo a doutrina que "one reson for their creation was to dilute the influence of the Monarch"20.

Um dos móveis, mais patentes, para o surgimento desses entes foi, evitar influência do poder político na regulamentação de questões específicas, pertinentes a segmentos da sociedade inglesa. Embora tenha havido extinção de várias dessas entidades e modificações de outras com as alterações do perfil do Estado, sobretudo o período "Tatcher", aquelas que exercem atividades reguladoras foram mantidas, aperfeiçoadas e até ampliadas, passando a exercer, inclusive, atividades antes exercidas p/entes compostos de membros eleitos segundo JENNINGS citado por ALDER, cinco seriam as principais razões para a criação desses entes:

" 1 . The need to provide cultural or personnal services supposedly free from the risk of political interference.

2. The desirability of non-political regulations of markets.

3. The regulation of independent profissions such as medicine and the law.

4. The provision of tchenical services.

5. The creation of informal judicial machinery for settling disputes". ${ }^{21}$

São traços bastante relevantes os acima indicados, sobretudo os de $n^{\circ} \mathrm{s} 1$ e 2 que ganham aceitabilidade nos principais sistemas jurídicos como justificadores da criação de entes reguladores autônomos, conforme ver-se-á oportunamente.

1.3.1 Na estrutura da Administração Pública britânica desenvolveu-se, também, a figura das "Executive Agencies", popularmente conhecidas como Next Steps Agencies. Essas entidades representam um dos referenciais adotados para o modelo brasileiro quando da reforma da estrutura da Administração Pública, em função do êxito alcançado no Reino Unido. Ali, WADE e FORSYTH as apontam como desenhadas e esboçadas para melhoria e aprimoramento dos serviços públicos, em proveito do cidadão e do Governo. Diferentemente dos Entes reguladores, não têm

18 JENKINS, Kate. A reforma do Serviço público no Reino Unido, in Reforma do Estado e Administraçāo Pública Gerencial [org. Luiz Carlos BRESSER PEREIRA e Peter SPINK]. Rio de Janeiro, 1998: Fundação Getúlio Vargas, p.205.

19 ALDER, John. Constitutional \& Administrative Law. London, 1989: Macmillan, p .224.

20 ALDER, John. Obra e p, citadas.

21 ALDER, John. Obra citada, p.225. 
atividade normativa. Seriam, segundo aqueles juristas," established on a semi-autonomous basis with a profissional manager, usually recruited outside the civil, as chief executive"22. Pautar-se-iam em contratos de gestão entre seus Dirigentes e o Ministério responsável e teriam uma administração financeira mais flexível, com controle menos intenso pelo Parlamento. Esses referenciais estão bem presentes nas Agências Executivas previstas no modelo brasileiro. ${ }^{23}$

As Agências, no Reino Unido, em fins de 1993 eram 92 e utilizavam cerca de $60 \%$ dos agentes públicos britânicos. ${ }^{24}$

Esse modelo britânico, aqui apenas referenciado é que serviu, juntamente com o norte americano, de fonte inspiradora para vários outros Estados Europeus e da América Latina.

1.4 Como exemplo de Estado no qual a figura das Agências, sobretudo das Reguladoras, causou forte impacto, poder-se-ia citar a França. Estado esse cujo modelo de Administração Pública fora relevante no passado como paradigma para Administrações Públicas de Estados como a Argentina e o Brasil, mesmo quando esses países a nível de arcabouço constitucional já haviam adotado como referencial o sistema norte americano, causando, ressalte-se, por vezes, esse hibridismo dificuldades ao conjunto.

A França, tradicionalmente, representa um modelo de administração pública unitária, com subordinação da administração às diretrizes do governo e a existência de uma estrutura recursal administrativa centralizadora. É um sistema já secular e que, como já salientado, serviu de inspiração a quase todas as administrações públicas latino americanas. Modelo esse, formado, basicamente, entre 1880 e 1945, com a idéia de unidade de Direção. Jean-Claude RICCI justifica essa subordinação argumentando no sentido que "La France est un État parlamentaire régi par une Constitution rigide. Dans ce cadre, le gouvernement, che de l'Administration est responsable de la politique devant le parlement, et donc nécessarirement, de la politique en matière administrative. C'est le pouvoir legislatif dans le cadre tracé par la Constitution, qui ordonne l'action gouvernamental et par voie de conséquence directe celle de l'administration". ${ }^{25}$

Trata-se de Administração estruturada a partir de Órgãos centrais, que são o Presidente da República, o Primeiro Ministro, os Ministros [compondo o governo] e outros órgãos de direção, estruturando-se os demais em duas linhas. A primeira

22 WADE, William; FORSYTH, Christopher. Administrative Law. Oxford, 1994: Clarendon, p.56.

23 Cf. BRESSER PEREIRA e SPINK, ao apresentarem o perfil do novo Estado brasileiro, no tocante ao exercício das atividades que lhe são próprias, afirmam que "nas atividades exclusivas estão o núcleo estratégico do Estado onde as políticas públicas são definidas $e$ os serviços de fiscalizaçāo e controle, onde o poder do Estado é exercido. Esses serviços devem ser realizados por Agências Executivas segundo o modelo britânico". [em Reforma do Estado e Administração Pública Gerencial,1998. Rio de Janeiro: FGV, p.11] .

$24 \mathrm{Cf}$. Les Agences, necessité fonctionnelle ou nouveaux demembrements de l'Etat? Seminaire de la promotion RENE CHAR. Paris: ENA, 1994, Annexe 3, p 01.

25 RICCI, Jean-Claude. L'Administration Publique Française, in L'Administration Publique en Europe. Paris, 1988: Ed. Du CNRS, p.85. 
a partir de critérios geográficos, surgindo as regiões, os departamentos e "les collectivités locales" e a Segunda tendo como critério a especialização de serviços, surgindo estabelecimentos públicos, em regime de direito público, e, os "établissements publics industriels e commerciaux" 26 Essa estrutura tradicional, aqui indicada de modo extremamente simplificado, foi alterada com a presença da autoridade administrativa independente, pois, a idéia básica de um ente autônomo, sem subordinação, ou vinculação a ministérios, afastada do sentido de unidade Administração, sem previsão na Constituição francesa de $1958 \mathrm{fez}$ surgir polêmicas e discussões sobre vários aspectos dessa nova figura, partindo, inclusive, da indagação se seriam efetivamente novas figuras, ou novas roupagens jurídicas atribuídas a figuras já existentes. A segunda questão sobre a compatibilidade delas com o regime constitucional francês. Outra indagação relevante foi sobre os níveis de controle judicial sobre esses Entes e a quarta sobre a natureza das normas por elas criadas. São questões que dizem respeito à compatibilidade dessas figuras ao sistema constitucional francês e que, por certo, necessariamente, são e serão, também, dúvidas a assaltar os publicistas brasileiros. Em relação a serem essas entidades compreendidas como uma nova categoria Jean-Louis AUTIN destaca que sua identificação obteve-se por via jurisprudencial, lembrando decisão do Conseil Constitutionnel, de 23/01/87 que reconheceu o Conseil de la Concurrence como um novo tipo de organismo administrativo não jurisdicional, ressaltando aquele autor que a identificação de uma entidade como autoridade administrativa independente tem aspecto de relevo em relação ao seu controle que é transferir o contencioso sobre seus atos, da justiça administrativa para a "juridiction judiciai$r e$ " inclusive no tocante a "le pouvoir de prononcer le sursis à exécution contre ces mêmes décisions". ${ }^{27} \mathrm{O}$ mesmo AUTIN viria, posteriormente, evidenciando a dificuldade teórica de se assegurar maior autonomia a essas entidades, mas ressalvando a importância pragmática de tal fato, a afirmar:

“on l'espère, que le contrôle du Conseil d'État n'était en espéce ni décisif ni suhaitable. Le cas de censure juridictionnelle sont apparus à la fois peu fréquents et peu significatifs, heureusement peut-on ajouter, car la mission de régulation des autorités indépendantes postule effectivité et immédiateté; elle ne résisterait pas à la phagocytose des nouvelles institutions dans l'ordre administratif classique. Sur le plan théorique, la figure d'autorités indépendantes de tout contrôle peut sans doute inquiéter au regard des exigences de l'État de droit et sembler inopportune dans une conjoncture où, à son sommet, le Conseil d'État tente de conforter son autorité. Mais il est rassurant de constater que les nouvelles

26 LAUBADÈRE, André de; VENEZIA, Jean-Claude; GAUDEMET, Yves. Traité de Droit Administratif. Tome 1, 1988. Paris: LGDJ, p.51 e segs.

27 AUTIN, Jean-Louis. Du Juge Administratif aux autorités administratives indépendantes: un autre mode de régulation,. In Revue du Droit Public et de la Science Politique en France et à l'étranger, 1988, p.1.217. 
institutions agissant sous le contrôle étroit de l'opinion acquièrent progressivement une légitimité dont elles étaient à l'origine dépourvues." 28

1.4.1 Como primeira Autoridade administrativa independente na França, a doutrina aponta de maneira uniforme, a Commision Nationale de l'Informatique et des Libertes criada pela Lei 78-17, de 06 de janeiro de 1978, cujo capitulo II estabelece:

“6.Une Commission Nationale de l'Informatique et des Libertés est instituée. Elle est chargée de veiller au respect des dispositions de la présente loi, notamment en informant toutes les personnes concernées de leurs droits et obligations, en se concernent avec elles et en contrôlant les applications de l'informatique aux traitements des informations nominatives. La commision dispose à cet effect d'un pouvoir réglementaire, dans les cas prévus par la présent loi

7... les dispositions de la Loi du 10 août 1922 relative au contrôle financier ne sont pas applicables 'a leur gestion...

8. La Commision Nationale de l'Informatique et des Libertés est une autorité administrative indépendante. Elle est composée de dix-sept membres nommés pour cinq ans ou pour la durée de leur mandat: ...

13. Dans l'exercice de leur attributions les membres de la Commision Nationale de l'Informatique et des libertés ne reçoivent d'instruction d'aucune autorité.

Comparando-se os traços principais acima indicados com a figura paradigmática norte americana verifica-se como distinção a inexistência de qualificação das entidades francesas como pessoas jurídicas ${ }^{29}$. Por outro lado, os elementos convergentes são extremamente relevantes: poder normativo ; autonomia financeira e administrativa em relação ao poder político; estabilidade dos integrantes do órgão de direção, etc.

28 AUTIN, Jean-Louis. Le contrôle des autorités Administratives indépendantes par le Conseil d'État, in p.1.565/1.566.

29 Apesar das divergências doutrinárias a tendência, na França é de qualificar as Autoridades Administrativas independentes como Órgāos especiais. Nesse sentido, o referido AUTIN e, dentre tantos outros, Didier LINOTTE, Achille MESTRE e Raphael ROMMI, sobre elas lecionando no sentido que "il est sûr en tout cas que, privées de la personnalité morale, elles devoient être considérées comme des prolongements de l'État, même si la loi du 11 juin 1983 les définit commes des "institutions administratives spécialisées de l'État... Ce Qui n'enterdut pas à certaines [la COB par example] d'ester en justice, ou de participer/elles sont plus nombreuses] à elaboration de règlements par l'État. Elles sont souvent investies de pouvoir de prendre des décisions individuelles, elles sont en tout cas des instances de régulation. pour l'heure manquant d'homogéneite, mais efficases et reconnues" [in Services Publics et Droit Public Economique. 2éme. ed., tome 1. Paris: LITEC, p.206. 
Há, atualmente, na França, várias dezenas de entes sob a forma de Autoridades Administrativas Independentes, podendo-se citar a título de exemplo: Agence Centrale des Organismes d'Intervention dans le Secteur Agricole [criada em 1983], Agence du Médicament [criada em 1993], Agence de lÉnvironnement et de la Maîtrise de l'Énergie [criada em 1991], Agence Française du sang [criada em 19921; Agence de Gestion du Spectre [criada em 1994].

Representam essas instituições, pois, uma forma cada vez mais presente na estrutura da Administração Pública Francesa, rompendo, sem dúvida com a estrutura tradicional anteriormente existente.

1.5 Também a Itália se viu influenciada por essa nova figura - A autoridade administrativa independente. A ela se refere CERULLI IRELLI como "il fenomeno emerso nell'esperienza più recentedelle c.d. autorità amministrative indipendenti, dotate, o meno di personalità giuridica, costituite dalla lege per governare determinati settori di amministrazione in senso sostanziale, secondo moduli organizzativi e funzionali del tutto svincolati da qualqsiasi relazione com l'Organizzacione ministeriale". ${ }^{30}$

Destaca esse jurista algo que representa, sem dúvida, uma das maiores dificuldades teóricas da figura da autoridade administrativa independente, ou ente regulador autônomo, sobretudo frente ao regime parlamentarista, quando lembra que "il modelo che ispira queste organizzacione è in qualche modo opposto a quello che aveva ispirato la costruzione dello Stato Parlamentarista, nel quale è principio fondamentale [come da noi espresse Cavour in formule limpidissime] che ogni articolazione, dell'organizzazione statale dipendalin misura più o meno intensa] da un ministro [cioè da un'autorità politica] che a sua volta possa risponderne in Parlamento I ciò̀ di fronte alle forze politiche reppresentative della comunità nazionale]. Il modelo che ispira la creazione delle c.d. autorita amministrative indipendenti tende viceversa alla dislocazione fuori dalla sfera di influenza politica di settori amministrativi ritenuti particolarmente delicati e delle relative organizzazioni". ${ }^{31}$

1.5.1 Apesar das dificuldades de compatibilização da figura da Autoridade Administrativa independente, ou da Agência Reguladora no regime parlamentarista, não se deve olvidar e, no caso, até antecipar, que tal construção teórica de adaptação é também árdua no regime presidencialista. A separação de poderes, ou a moderna teoria da separação das funções sofre, por vezes, alguns revezes com a teoria dos entes reguladores autônomos. O controle político sobre esse tipo de entidade, bastante atenuado, não é, facilmente compatibilizado com a idéia de legitimação democrática dos órgãos compostos por titulares de mandatos eletivos. Elisabetta BANI, ao examinar a figura da Autoridade Administrativa independente, na Itália, a associa a desregulação [desregulation], no sentido da tendência reducionista de produção de normas jurídicas por Órgãos políticos do Estado, possibilitando regramentos por Órgãos específicos, segmentos especializados, através de entes com maior conhecimento técnico. Poder-se-iam apontar como alguns exemplos dessas entidades, na- 
quele Estado, dentre outros, La commissione di Garanzia Dirito di Sciopero Icriada pela Lei 146, de 12.06.90], Garante Radiodiffusine editoria [criada pela Lei 223, de 06.08.90], a Autorità Garante della Concorrenza e del Mercato [criada pela Lei 287, de 10.10.90]. BANI aponta, que apesar das variações legislativas em relação aos entes criados [commissione, Istituto, Autorità, Agenzia etc.] teriam elas características básicas convergentes:

"1. Independenza dalle strutture burocratico-ministeriali dell'amministrazione tradizionale...

2. ...Tali organi vengano ritenuti titolari di attività amministrative o giurisdizionali viene dato maggiore o minore rilievo alla loro effetiva indipendenza dal Governo...

3... l'altro tratto caratteristico...è l'elevato grado di competenza dei membri di tali soggeti di grande profissionalità e integrità". ${ }^{32}$

Essa autora, citando AMORELLI [L'Amministrazione c/ funzione regolatorie: Le Autorità di disciplina della concurrenza sul piano interno e comunitario, in Riv. It. Dir. Pubbl. Comunitario, 04/1991, p.947] também ressalta a dificuldade de adequação do modelo ao sistema constitucional italiano. Tal dificuldade, constata-se, inclusive, para enquadramento da produção normativa desses entes como atos regulamentares. A doutrina procura responder a esse questionamento entendendo como forma de compatibilização para os fins da Constituição Italiana, que tais entes seriam "análogos" ao Poder Executivo, fundados em "attribuzioni di funzioni". Nessa trilha, dentre outras, a lição de Gustavo ZAGREBELSKY $\cdot{ }^{33}$ Consolida-se, pois, na Itália, de modo similar ao modelo francês, a figura da autoridade administrativa independente, visando atender a essa necessidade de disciplinamento setorizado e técnico de atividades reguladas pelo Estado e cuja regulação exige uma disciplina mais técnica e isenta de conotação política. Constata-se, sem dificuldade a coincidência de áreas reguladas por esses tipos de entidades nos vários Estados da Europa ocidental.

Vale, entretanto, a advertência de LONGOBARDI, também pertinente em Estados como o Brasil. Ressalta aquele Mestre de Aquilla:

"les risques liès a la creation d'autoritès de ce type dans notre ordonnancement pourraient être nombreaux et graves- on les imagine facilement-si cette création n' était pas accompagnée par une demande exigeante de garanties de procédure d'organization et de participation, de transparence de l'action, de

32 BANI, Elisabetta. Stato Regolatore e autorità independenti. In Diritto Pubblico dell'Economia. Padova, 1994: Cedam, p. 14/15.

33 ZAGREBELSKY, Gustavo. Manuale di diritto Costituzionale, I [Il sistema della fonti del diritto]. Torino, 1993: UTET, 213. 
contrôle, appropriés, d'efficience et de compétence technique. La recherche de ces sources de légitimation, complementaires d'une légitimation democratique au degré minimum, pourrait, en revanche, amorcer un cercle vertueux pour l'ensamble de notre administration". ${ }^{34}$

Pode-se afirmar, em relação a esses Entes da existência de características convergentes, e também de proximidade quanto aos questionamentos decorrentes da adoção daqueles, em outros Estados Europeus.

1.6 Em Portugal, autoridades administrativas independentes, ou AAI são conceituadas por SANTOS, GONÇALVES e LEITÃO MARQUES como "organismos com funções administrativas especializadas e com independência orgânica e funcional- ou seja, não submetidos ao controlo hierárquico, nem à tutela de outro órgão administrativo, ou governamental" caracterizando-se pelo exercício de funções reguladoras["incluindo poderes normativos, ainda que limitados, de fiscalização e sancionatórios"]. ${ }^{35}$

A doutrina portuguesa ressalta outro aspecto em relação a esses entes que é o fato de não terem necessariamente a mesma natureza jurídica, importando como traços aglutinadores apresentarem algumas "condições", no dizer dos citados SANTOS, GONÇALVES e LEITÃO MARQUES, que seriam:

"As primeiras relacionam-se com os membros que as compõem, tais como a forma de sua designação; a duração do respectivo mandato e a sua irrevogabilidade e não renovação; o pluralismo de pontos de vista representados; a incompatibilidade com outras funções.

As segundas são as que asseguram a sua independência funcional. Para além da ausência de poder hierárquico, há que referir a autonomia de organização e funcionamento; a capacidade para definir o seu próprio regulamento; a autonomia do ponto de vista logístico assente na disponibilidade de recursos para desenvolver sua atividade." ${ }^{36}$

A matéria pertinente à disciplina dos Entes reguladores autônomos é, também em Portugal, objeto de preocupação da doutrina, inclusive em sede de temas relevantes como o dos limites jurídicos do poder regulamentar dos entes autônomos face ao sistema constitucional vigente. ${ }^{37}$

34 LONGOBARDI, Nino. Autorités Administratives indépendantes et position institutionnelle de l'Administration, in RFD adm. 11 (02) mars-avrs, 1995, p.389.

35 SANTOS, António Carlos; GONÇALVES, Maria Eduarda; LEITĀO MARQUES, Maria Manoel. Direito Económico. Coimbra,1995: Almedina, p.142.

36 SANTOS, António Carlos; GONÇALVES, Maria Eduarda; LEITĀO MARQUES, Maria Manoel. Obra citada, p.144.

37 Sobre o regime constitucional dos regulamentos em Portugal, consulte-se JJ GOMES CANOTILHO. Direito Constitucional e teoria da Constituiçāo, $2^{2}$ ed. Coimbra, 1998: Almedina, p.732 e segs. 
O estudo dos Entes Reguladores autônomos, em Portugal, é, entretanto, matéria recente, tanto que não abordado por tradicionais e excelentes manuais como o de Marcello CAETANO ${ }^{38}$, mesmo atualizado; o de Diogo FREITAS DO AMARAL ${ }^{39}$. Já Vital MOREIRA e o citado CANOTILHO ressaltam, ao comentarem o Art. 266, da vigente Constituição Portuguesa, estarem, também eles sujeitos à observância de princípios constitucionais como os da igualdade, da proporcionalidade, da justiça e da impessoalidade. ${ }^{40}$

Resumidamente, pode-se afirmar que as autoridades administrativas independentes apresentam, em Portugal as características básicas do modelo adotado na Itália e na França.

Poder-se-ia, ainda, referenciar vários outros ordenamentos jurídicos europeus que incorporaram essa figura.

A título de referência poder-se-ia, ainda, citar a Suécia que " a probablement dans le monde la tradicion la plus ancienne e la plus marquée d'organisation administrative sous forme d'agences. ${ }^{41}$

Ali são encontradas mais de oitenta desses entes, normalmente dirigidas por um Diretor geral, nomeado por seis anos, mas exonerável "ad nutu", atuam em áreas setorizadas e especializadas, tem maior nível de autonomia, inclusive de gestão e financeira, enfim, embora não alcançando o nivel de autonomia das "Agencies" norte americanas, exprimem um grau de autonomia maior que a figura das autarquias tradicionais brasileiras.

1.7 A figura dos entes reguladores autônomos também migrou para a América Latina, sobretudo a partir do fenômeno da desestatização, ocorrido e ora ocorrendo, em Estados como a Argentina e o Brasil. Desestatização essa motivada por fatores endógenos e exógenos, com a conseqüente redução dos papéis do Estado, inclusive, no tocante ao exercício das funções administrativas atípicas, ou ditas, impróprias do Estado, a partir da segunda metade da década de oitenta e sobretudo na presente década, embora já, antes desse período fossem encontradas alguns exemplos isolados, ou, pelo menos algumas características em embrião, dessas entidades reguladoras.

$1.8 \mathrm{Na}$ Argentina, tal como no Brasil, o surgimento das "agências", ou dos entes reguladores autônomos teve como ponto inicial o processo de privatização, ou de desestatização. Nesse sentido leciona Jorge GARCIA SARMIENTO ao destacar

38 CAETANO, Marcello.Manual de Direito Administrativo.10 $0^{\circ}$ d., 6 reimpressão, vol, 1, 1997 , Coimbra: Almedina.

39 AMARAL, Diogo Freitas. Curso de Direito Administrativo. Vol I, Coimbra: Almedina e os demais pela AAFDL [Lisboa].

40 CANOTILHO, JJ Gomes; MOREIRA, Vital. Constituição da República Portuguesa anotada. Coimbra, 1993: Coimbra ed., p.921.

41 LES AGENCES, NECESSITÉ FONCTIONNELLE OU NOUVEAUX DÉMEMBREMENTS DE L'ÉTAT? Seminaire de la Promotion "Rene Char". Paris, 1994: ENA [Annexe 4: Les Agences en Suède]. 
que "el processo de privatizaciones iniciado en 1989 há incluido, com el objeto de regular y controlar las actividades privatizadas, la creación de los ahora denominados entes reguladores. Estos entes se han inspirado en las agencias y comisiones del derecho norteamericano, y como aquéllas, se distinguen por concentrar funciones normativas, jurisdiccionales y administrativas, com pretensiones de neutralidad y independencia del Poder político junto a la especialización técnica." 42 Destaca, ainda, aquele Jurista, fenômeno também apontado no Brasil pela doutrina, "pese a la inspiración norteamericana que se les reconoce, lo cierto es que han adoptado para su naturaleza jurídica, la autarquia de raigambre francesa $Y$ esse carácter autárquico a diferencia de las agencias norteamericanas, implica um control de sus decisiones por vía del recurso de alzada"43. Essa idéia que a Agência seria enquadrável na figura da autarquia, embora implique em dificuldades teóricas, é aceito pela doutrina argentina. Juan Carlos CASSAGNE, p.e., após examinar a criação dos Entes reguladores de gás, eletricidade e água; e, a Comisión Nacional de Telecomunicaciones defendeu que "la condición jurídica de estos entes es la propia de las entidades autárquicas pues se trata de descentralizaciones juridicas del Estado que participan de la naturaleza pública de éste, perteneciendo, en realidad, a su organización administrativa pese a su personalidad diferenciada." 44 [destaque inexistente no original]. Faz CASSAGNE a mesma ressalva de SARMIENTO GARCIA quanto à autonomia dessas entidades, em cotejo com o modelo norte americano, ao destacar que " como es sabido, autarquía no significa independencia. La entidad autárquica se halla vinculada a la administración central por el contrl de tutela que se encauza procesalmente a través del recurso de alzada. Esto es una importante diferencia de règimen juridico entre nuestros entes regulatorios y las agencias regulatorias del derecho norteamericano cuyo grado de independencia es mayor, a raíz de que sus actos no se hallan sujetos a la revisión por parte del Poder Ejecutivo. ${ }^{45}$

É relevante, por outro lado, por em destaque que a Constituição Argentina, expressamente, fixou a subordinação do poder regulador ao princípio da legalidade, ao menos em termos de fixação dos limites dessa produção normativa secundária. Assim dispõe a Constituição Argentina em seu Art.42 [pós reforma de 1994]:

...La legislación establecerá procedimientos eficaces para la prevención y solución de conflictos, y LOS MARCOS REGULATORIOS DE LOS SERVICIOS PUBLICOS DE COMPETENCIA NACIONAL...

BIDART CAMPOS, ao comentar esse dispositivo constitucional ressalta que "estes organismos controladores han de tener facultad en el doble ámbito: para

42 GARCIA, Jorge Sarmiento. Concesion de Servicios Publicos. Buenos Aires, 1996: Ediciones Ciudad Argentina, p.146.

43 GARCIA, Jorge Sarmiento. Obra e p. citadas.

44 CASSSAGNE, Juan Carlos. Derecho Administrativo. Tomo II, $5^{2}$ ed, atualizada de acordo com a reforma Constitucional de 1994. Buenos Aires, 1996: Abeledo Perrot, p.492.

45 "CASSAGNE, Juan Carlos. Obra citada, p.493. 
prevenir y solucionar conflictos y para fiscalizar y exigir que las prestaciones de bienes y servicios se encuadren en el marco regulatorio fijado por la Ley. ${ }^{46}$

1.8.1 São, sem duvida, os entes reguladores argentinos dotados de menor autonomia em relação à administração central que o paradigma norte americano, possibilitando o controle pelos Ministérios. Embora seja de ressaltar-se que esses entes reguladores apresentam-se com autonomia mais acentuada em relação às autarquias tradicionais. O que se constata, em verdade, é uma certa insegurança da doutrina em construir o adequado perfil desses entes, inclusive face às mudanças recentes do ordenamento jurídico, ainda não adequadamente assimiladas. Há toda uma construção por se fazer, ou, pelo menos por completar.

Esse fato já era destacado por Agustín GORDILLO, afirmando estar a Argentina neste "tema, como en tantos otros, ante una realidad a mitad de camino entre el sistema preconstitucional y el que debe ponerse en marcha com la nueva Constitución de 1994. Por de pronto, falta aún dictar el resto de los marcos reguladores legales exigidos por el artículo 42 lpor ahora existen el del gas y la eletricidad, leyes 24.076 y 24.065 J readecuar los preexistentes, y talvez como igualmente se propone dictar una ley marco que establezca los trazos generales de su funcionamiento, sin dependencia del Poder Ejecutivo ni facultades reglamentarias de éste sobre tales entes o sus relaciones com los concesionarios sujetos al control." 47

Destaca, ainda, aquele notável jurista, da dificuldade de apresentar generalizações, deduções sobre os entes reguladores em função da pluralidade de textos, nem sempre bem sistematizados. Faz algumas ponderações, entretanto, que merecem atenção, inclusive para o caso brasileiro. Uma delas é que a faculdade regulatória deve ser considerada distintamente do poder concedente e outra, decorrente, no sentido que "el que concede, outorga un monopolio no debe ser el que lo controle. Es pues el mismo principio actualizado, de la división de poderes, y el sistema de frenos y contrapesos, que nuestra Constitución perfecciona ${ }^{48}$

1.8.2 Verifica-se, pois, no estágio atual, que em relação às Agências, ou aos entes reguladores autônomos, o direito argentino se encontra em relação ao direito brasileiro, mais evoluído, com maior densidade doutrinária etc. Tal se justifica, pois, o surgimento desses entes aconteceu e acontece em função das desestatizações e privatizações que se iniciaram naquele país antes do seu início de processo similar no Brasil. Mas, mesmo assim, ainda persistem inúmeras questões por abordar e por terem melhor tratamento jurisprudencial e doutrinário acerca dos entes reguladores

46 "CAMPOS, German J. Bidart. Tratado Elemental de Derecho Constitucional Argentino, tomo VI [La reforma constitucional de 1994]. Buenos Aires, 1995: Ediar, p.309.

47 GORDILLO, Agustín. Tratado de Derecho Administrativo. Parte General, tomo I, $3{ }^{\star}$ Ed. Buenos Aires, Bogotá, Caracas, México DF, 1995: Ediciones MACCHI, p.XV, 1.

48 GORDILLO, Agustín. Obra citada, p.XV-4. 
+ argentinos. Já se pode, entretanto, traçar alguns marcos identificadores daqueles, na Argentina: 1. Têm menor autonomia que as "Agencies" norte americanas; 2. Estão, ainda, ligadas à tradicional figura das autarquias, das quais são consideradas espécies; 3 . Têm capacidade normativa, mas subordinada ao princípio da legalidade; 4. Surgiram com o fenômeno da privatização, ou desestatização e, também, com a desregulamentação, que seria mais adequadamente denominada de "deslegalização", pois significa redução da disciplina das relações jurídicas, atos, etc. por lei e sua regulação por entes setoriais; 5 . Não devem sofrer influência política, devendo seu poder normativo ter caráter basicamente técnico. Sem dúvida a figura do recurso de alçada enfraquece a autonomia dessas entidades e a neutralidade política pretendida.

Concluindo essa breve referência a outros ordenamentos jurídicos, pode-se afirmar que a figura da Agência, do ente regulador autônomo, independente da denominação [Agency, Commission etc] representa uma das maiores contribuições do "Administrative Law" norte americano, juntamente com o instituto da procedimentalização, expresso sobretudo no Federal APA de 1946, para o direito administrativo moderno, tanto europeu, como latino americano, pode-se afirmar até para a teoria geral do direito administrativo. Sabido é, entretanto, que aquela figura encontrou dificuldades de adaptação em vários ordenamentos jurídicos, não só face aos sistemas jurídicos existentes, mas, inclusive, face às molduras constitucionais nem sempre adequadas, ou compatíveis, com a figura do Ente Regulador autônomo. $\mathrm{O}$ princípio da legalidade apresenta-se, por vezes, se não devidamente compatibilizado, como um dos "entraves" ao adequado funcionamento dessas entidades. Sem dúvida, foi necessário que se desenvolvesse a idéia de desregulação pelos Entes políticos, para que se pudessem desenvolver as normatizações secundárias, setoriais, especializadas, por entes reguladores autônomos, em processo também chamado de deslegalização.

Outro aspecto relevante a ser observado é da necessidade desses Entes autônomos que exercem, como decorrência da normatização setorial, poder de polícia, verificando a compatibilidade de ações, condutas, omissões, relações jurídicas com a previsão normativa fiscalizando e impondo sanções, em procedimentos ablativos regulares, estarem aptos, devidamente estruturados para exercerem esses papéis, sem ingerência do poder político, ou do poder econômico, assegurando aos administrados os direitos constitucionalmente previstos, inclusive procedimentais, sem perda de efetividade. Outro aspecto a se observar e se esse tipo de ente é, de fato, compatível com a estrutura estatal de um Estado subdesenvolvido, assolado por focos de corrupção e empreguismo, com barganhas políticas em troca de favores, inclusive com partilha de cargos. 